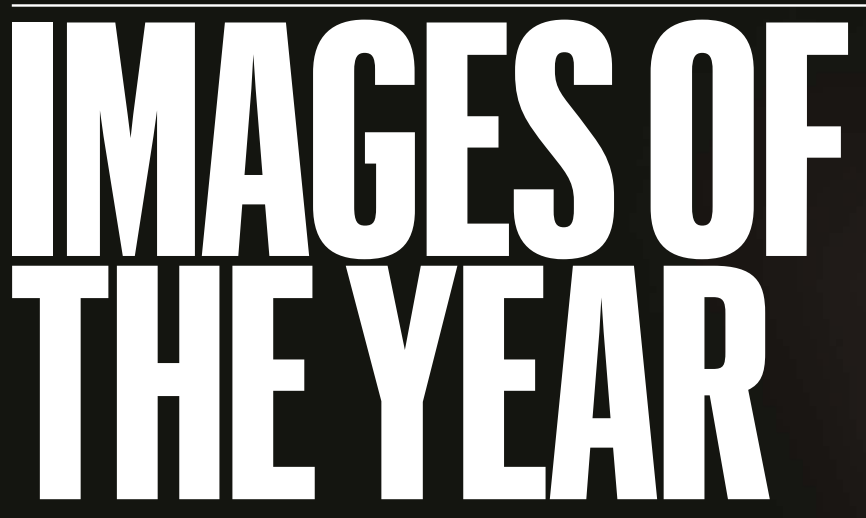

2019 will be remembered as the year humanity captured the first-ever image of a black hole. The year also brought fresh views of some of Earth's smallest living creatures and ominous signs of its changing climate. Here are the most striking shots from science and the natural world that caught the attention of Nature's news team.

Images selected by Nature's art editors

Text by Nisha Gaind and Ewen Callaway 


\section{Go with the flow}

French researchers carved a labyrinth of microfluidic chambers in a silicon wafer to mimic blood flows in circulatory networks. Biophysicist Benoît Charlot at the University of Montpellier, France, captured this image using a scanning electron microscope.

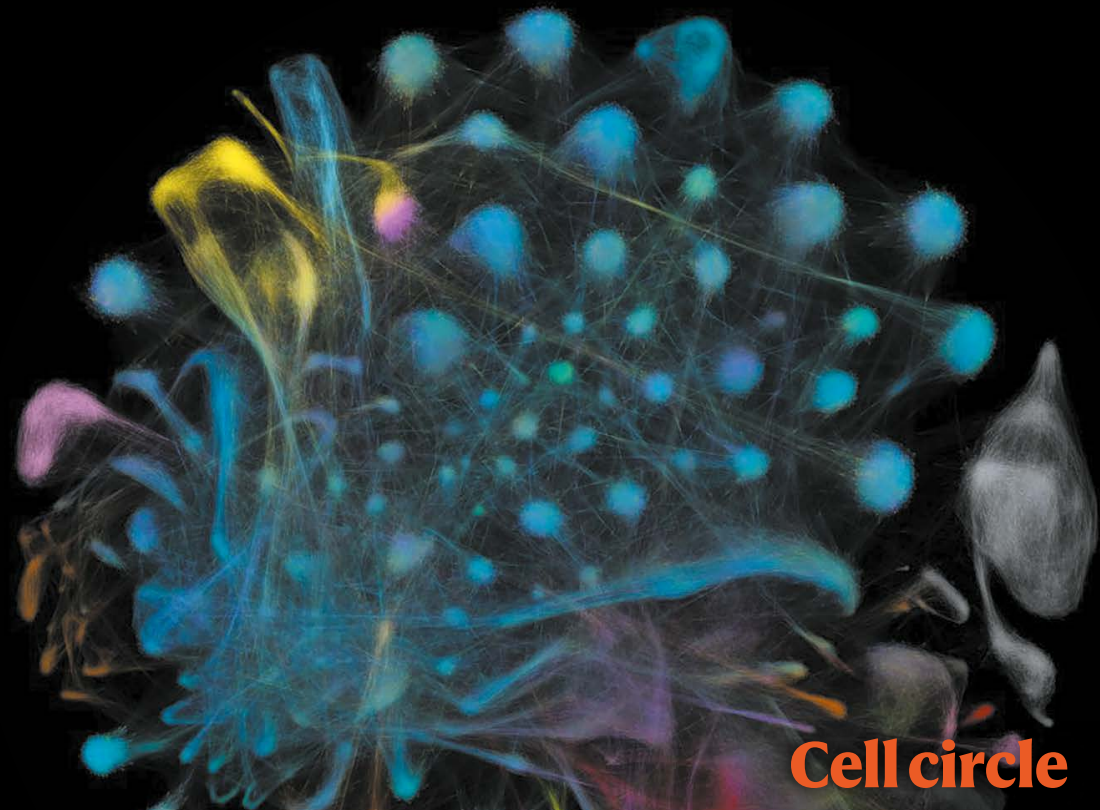

Each tiny dot in this circle represents one of around 100,000 cells from rhesus macaque monkeys. Cells with similar traits cluster together, and each colour represents different tissues such as the thymus and lymph nodes (blue) and bone marrow (red).

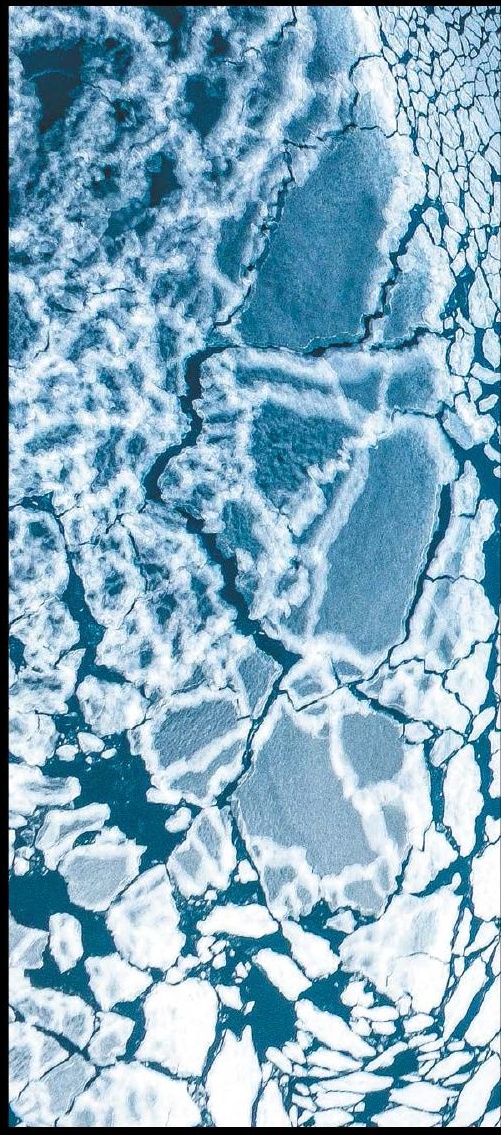




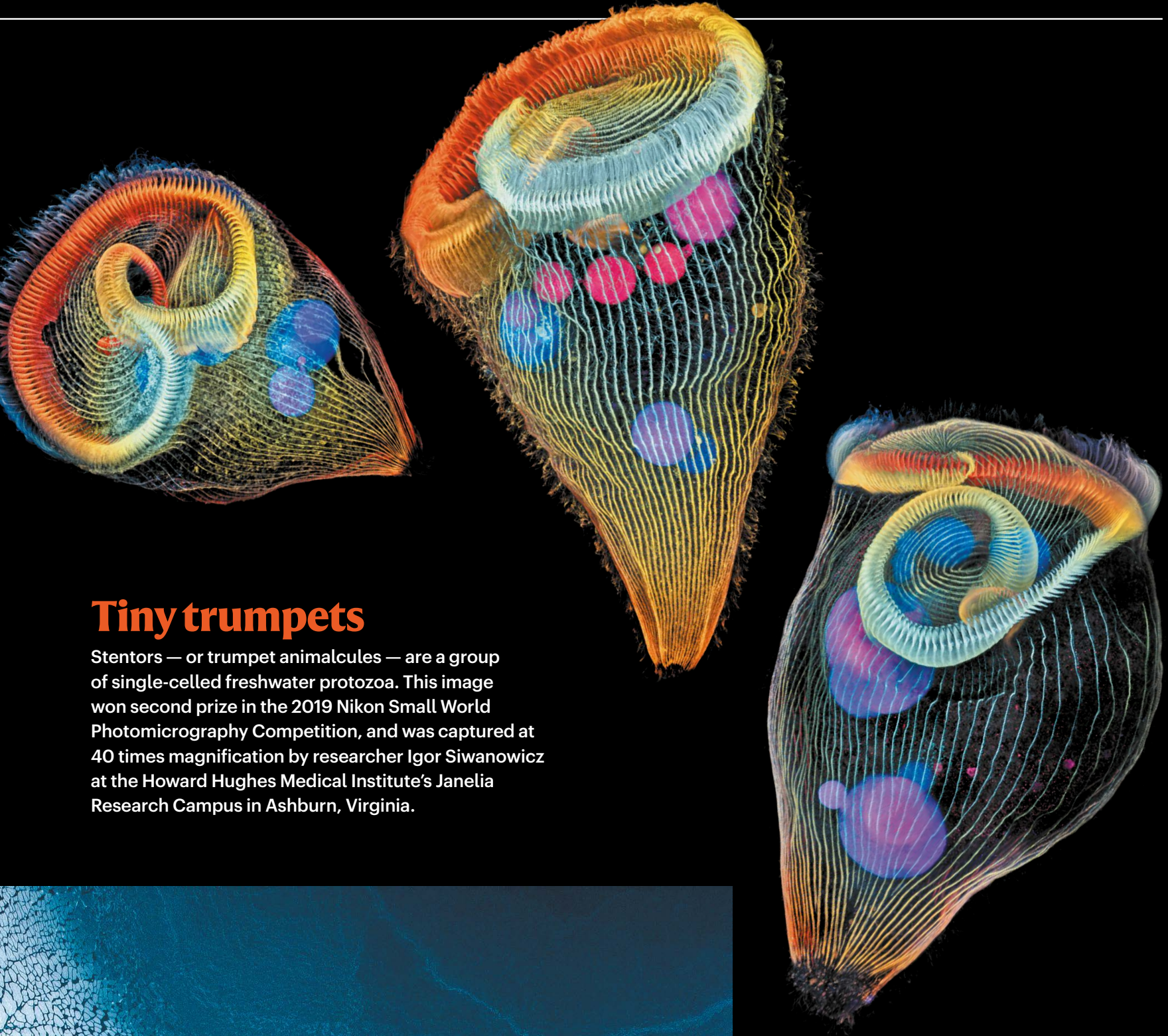

Stentors - or trumpet animalcules - are a group of single-celled freshwater protozoa. This image Photomicrography Competition, and was captured at 40 times magnification by researcher Igor Siwanowicz at the Howard Hughes Medical Institute's Janelia Research Campus in Ashburn, Virginia.

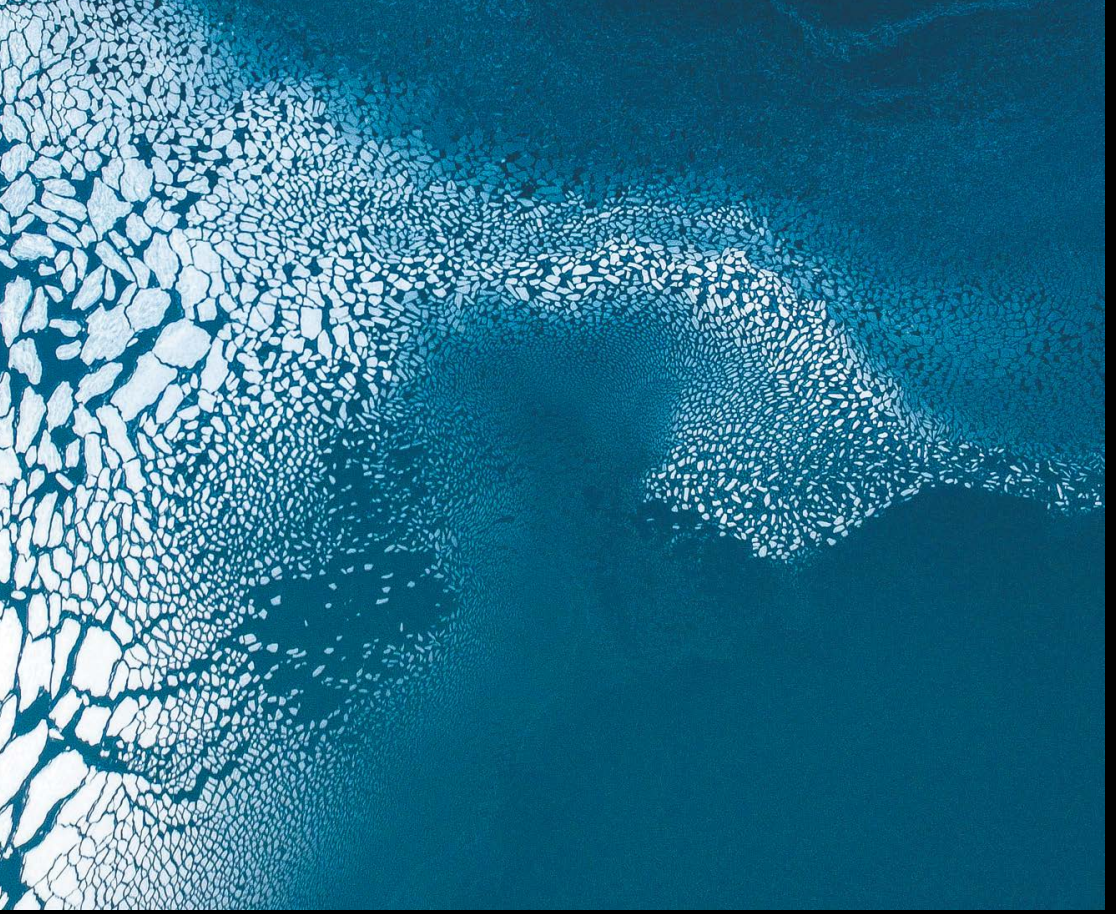

\section{Onthinice}

This aerial view of the sea ice in

East Greenland was captured by photographer Florian Ledoux using a drone. Low levels of winter snow cover, heatwaves in the spring and a sunny summer all contributed to significant melting of Greenland's ice sheet in 2019. 


\section{Holehorizon}

The Event Horizon Telescope

collaboration unveiled this first direct image of a black hole and its event

horizon in April. The team used eight

radio observatories to capture the ring

of light around the void, which is at the centre of the galaxy Messier 87. 


\section{Friends reunited}

Astronaut Christina Koch took this picture of the Soyuz spacecraft carrying her NASA colleague Jessica Meir as it approached the International Space Station (ISS). On 18 October, the pair performed history's first all-female spacewalk, to repair a faulty battery unit on the ISS.

\section{Out of its shell}

This fluorescent visualization of a turtle embryo was the winner of the 2019 Nikon Small World Photomicrography Competition. Microscopists Teresa Zgoda and Teresa Kugler stitched together and stacked hundreds of stereomicroscope images of the roughly 2.5-centimetre-long embryo.
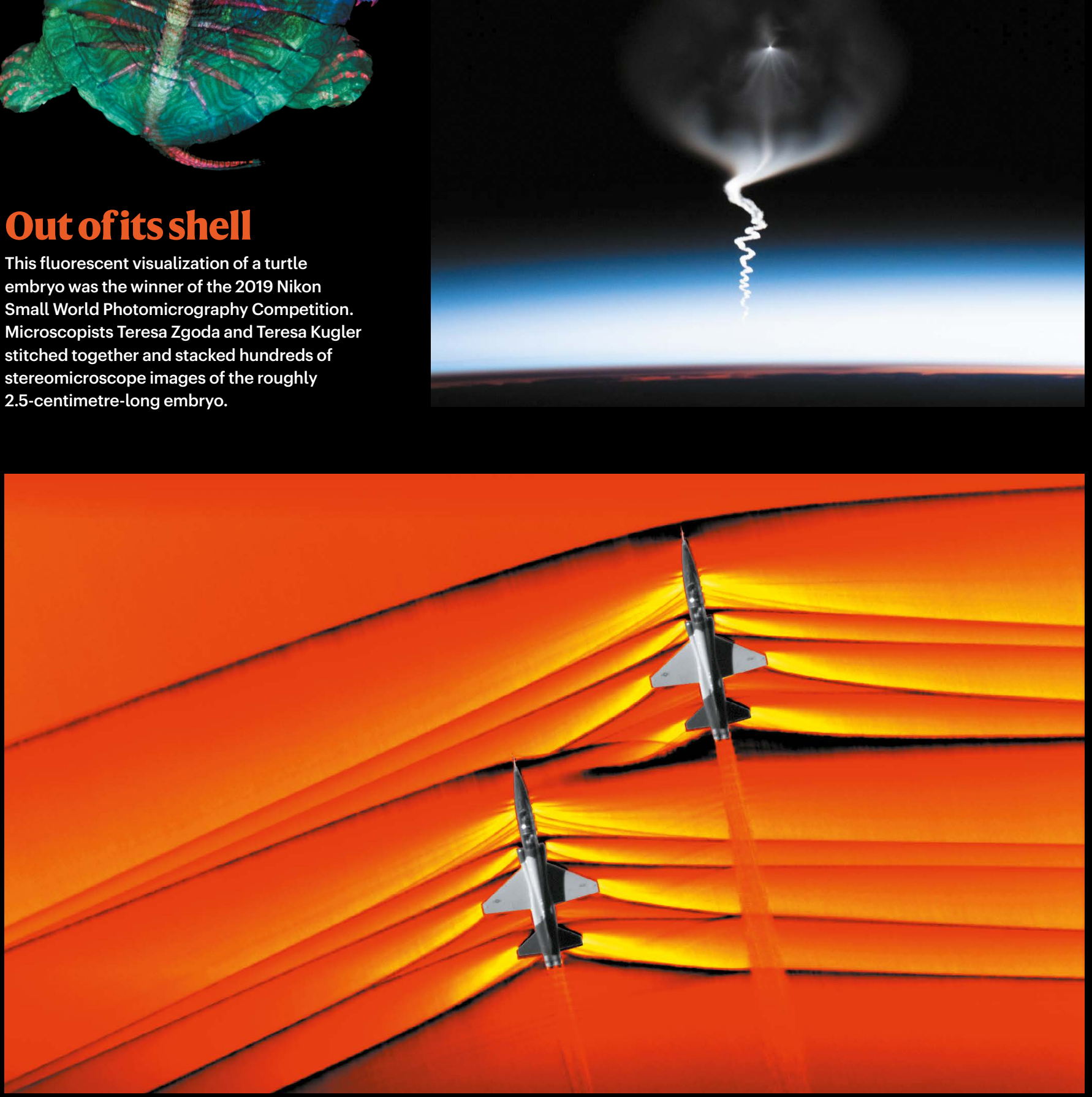

\section{Good vibrations}

This false-colour image shows shockwaves emanating from supersonic US T-38 Talon aircraft, and was captured by NASA staff using an experimental technique from an aeroplane above. It shows the rapid changes in air pressure that cause people to hear sonic booms. The data will help aeronautical engineers to design quieter supersonic planes. 


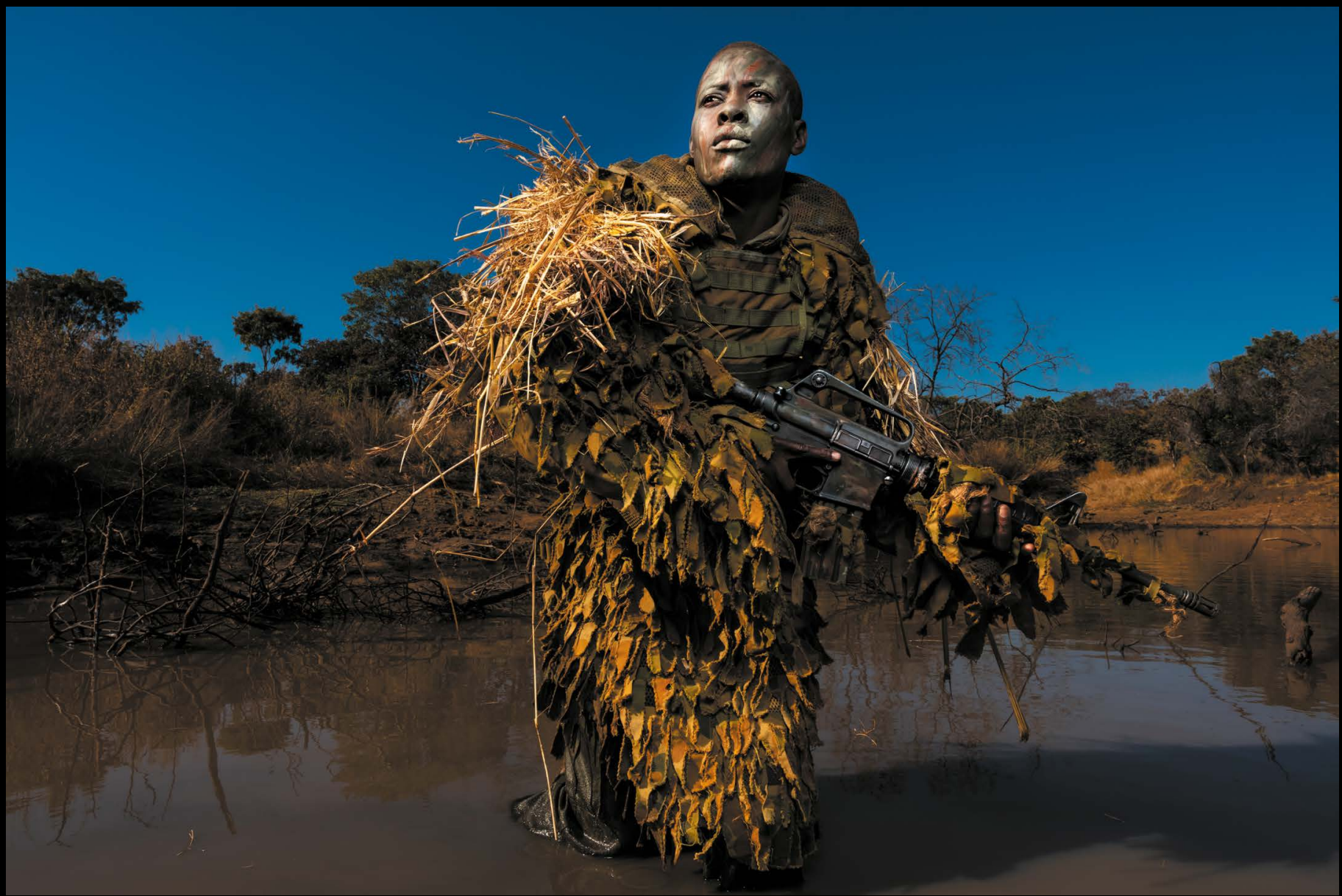

\section{Braveone}

Petronella Chigumbura is a member of the Akashinga, or 'brave ones', an all-female anti-poaching unit. They patrol Zimbabwe's Phundundu Wildlife Area in the Zambezi Valley, where elephant poaching is common.

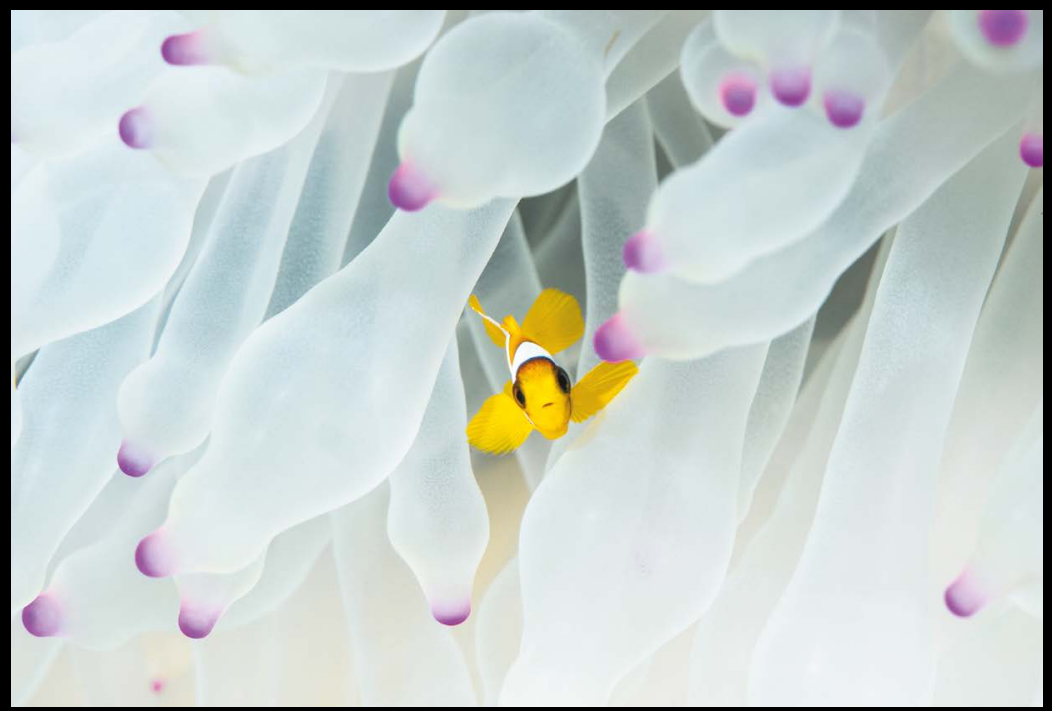

\section{Anyone home?}

A fish explores a bleached sea anemone in the Red Sea, off the coast of Saudi Arabia. Like corals, anemones form symbiotic relationships with algae that are disrupted when oceans get too warm, causing the anemone to expel the algae and become colourless.

\section{Weedram}

This web-like microstructure is made of fats left behind after researchers evaporated a 1-microlitre drop of diluted bourbon whisky. The fats dissolve in higher-strength spirits but turn a drink cloudy when water is added.

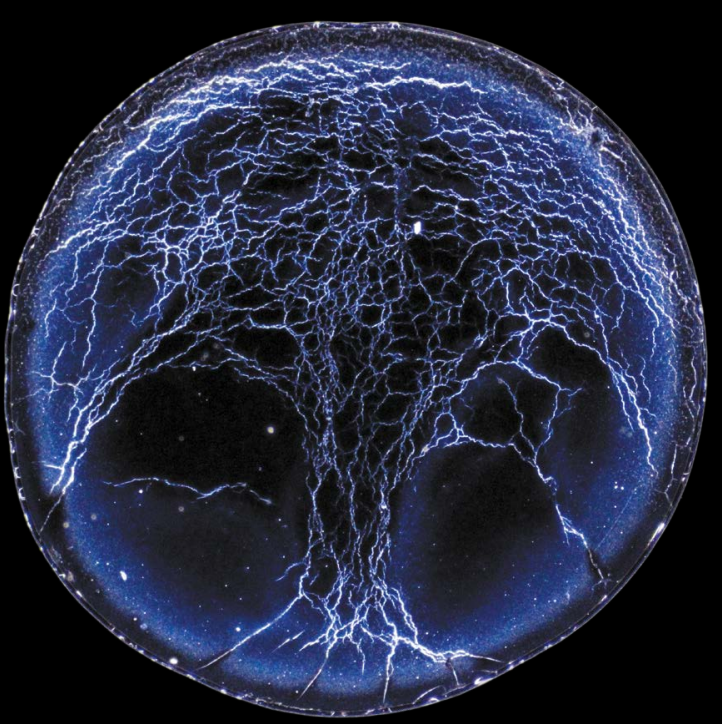

